\title{
Effects of native pollinator specialization, self- compatibility and flowering duration of European plant species on their invasiveness elsewhere
}

\author{
Thomas Chrobock ${ }^{1,2 \dagger *}$, Christiane N. Weiner ${ }^{3}$, Michael Werner ${ }^{3}$, Nico Blüthgen $^{3} \neq$, \\ Markus Fischer ${ }^{1,2,4}$ and Mark van Kleunen ${ }^{5}$ \\ ${ }^{1}$ Institute of Plant Sciences, University of Bern, Altenbergrain 21, 3013 Bern, Switzerland; ${ }^{2}$ Oeschger Centre for \\ Climate Change Research, University of Bern, Zähringerstrasse 25, 3012 Bern, Switzerland; ${ }^{3}$ Department of Animal \\ Ecology and Tropical Biology, Biozentrum, University of Würzburg, Am Hubland, 97074 Würzburg, Germany; \\ ${ }^{4}$ Botanical Garden of the University of Bern, Altenbergrain 21, 3013 Bern, Switzerland; and ${ }^{5}$ Ecology Department of \\ Biology, University of Konstanz, Universitätsstrasse 10, 78457 Konstanz, Germany
}

\begin{abstract}
Summary
1. When entomophilous plants are introduced to a new region, they may leave behind their usual pollinators. In particular, plant species with specialized pollination may then be less likely to establish and spread (i.e. become invasive). Moreover, other reproductive characteristics such as selfcompatibility and flowering duration may also affect invasion success.

2. Here, we specifically asked whether plant species' specialization towards pollinator species and families, respectively, as measured in the native range, self-compatibility, flowering duration and their interactions are related to the degree of invasion (i.e. a measure of regional abundance) in nonnative regions.

3. We used plant-pollinator interaction data from 119 German grassland sites to calculate unbiased indices of plant specialization towards pollinator species and families for 118 European plant species. We related these specialization indices, flowering duration, self-compatibility and their interactions to the degree of invasion of each species in seven large countries on four non-Eurasian continents.

4. In all models, plant species with long flowering durations had the highest degree of invasion. The best model included the specialization index based on pollinator species instead of the one based on pollinator families. Specialization towards pollinator species had a marginally significant positive effect on the degree of invasion in non-native regions for self-compatible, but not for selfincompatible species.

5. Synthesis. We showed that long flowering duration is related to the degree of invasion in other parts of the world, and a trend that pollinator generalization in the native range may interact with self-compatibility in determining the degree of invasion. Therefore, we conclude that such reproductive characteristics should be considered in risk assessment and management of introduced plant species.
\end{abstract}

Key-words: distribution, flowering period, generalization, introduced range, invasion ecology, plant invasion, plant-pollinator interaction, pollinators, self-fertilization, specialization

*Correspondence author. E mail: thomas.chrobock@ips.unibe.ch $\dagger$ Present address: Carl Zeiss Naturzentrum Amrum, Strunwai 31, 25946, Norddorf auf Amrum, Germany.

$\$$ Present address: Ecological Networks, Department of Biology, Technische Universitat Darmstadt, Schnittspahnstrasse 3, 64287, Darms tadt, Germany.

\section{Introduction}

Seed production of the majority $(>80 \%)$ of flowering plant species relies, at least partly, on insect pollination (Ollerton, Winfree \& Tarrant 2011). Many entomophilous alien species, thus, can only reproduce, establish naturalized populations and spread (i.e. become invasive sensu Richardson et al. 2000a; Blackburn et al. 2011), if effective pollinators also 
occur in the non native region (Parker \& Haubensak 2002). These may be pollinators native to this region (Muñoz \& Cavieres 2008; Rodger, van Kleunen \& Johnson 2010), intro duced pollinators (Stout, Kells \& Goulson 2002; Gross et al. 2010) or both (Parker 1997). A shared evolutionary history of both plant and pollinator is thus not a prerequisite (Gross et al. 2010; Pattemore \& Wilcove 2012). However, whether an introduced plant species will attract pollinators in the new range probably depends on its level of specialization towards pollinators (Baker 1974).

It has been suggested that most invasive plant species are not pollinator limited (Richardson et al. 2000b; but see Parker 1997) and that they are well integrated into plant pollinator networks in the non native range (Memmott \& Waser 2002; Vilà et al. 2009). These and other studies on the pollination of alien plant species mostly focused on highly invasive ones and neglected less successful alien species. As a consequence, it is not clear whether there is a relationship between the degree of invasion (i.e. regional abundance) and specialization towards pollinators. Moreover, if one wants to predict inva siveness of plant species in non native ranges, it is useful to assess specialization in the native range and whether it relates to species' invasiveness elsewhere (van Kleunen et al. 2010). Then, it will be possible to explicitly test whether generalized plant species have a higher degree of invasion than special ized species in regions where they are not native. So far, this native range approach has never been applied with respect to pollinator specialization.

Quantifying plant specialization to pollinators is notoriously difficult (Waser et al. 1996; Fenster et al. 2004). One can cal culate specialization indices based on the diversity of pollina tor species or based on the diversity of pollinator families (Ollerton et al. 2007). Although pollinator species within a family may belong to different functional groups (e.g. long tongued bees, short tongued bees, other Hymenoptera; see Fenster et al. 2004), they are usually more likely to be func tionally analogous than species of different families (Ollerton et al. 2007). Therefore, the diversity of pollinator families would take into account that a plant species pollinated by two butterfly species is functionally more specialized than a plant species pollinated by one butterfly and one bee species. 'Mere' numbers of pollinator species and families visiting a plant species (Waser et al. 1996; Ollerton et al. 2007) or the number of links of a plant species with pollinators in a plant pollinator network (Fontaine, Thébault \& Dajoz 2009) may already serve as proxies of specialization. However, these metrics inevitably depend on observation frequency and, con sequently, may be biased in that more common (or more attractive) species are regarded as more generalized (Blüthgen 2010). Moreover, these estimates of specialization do not take into account the uniqueness of a plant pollinator interaction (i.e. whether a plant is visited by a specialized or a general ized pollinator) and that two plant species may have the same number of (identical) pollinator species but differ in special ization because one of them is equally visited by all pollina tors and the other predominantly by one of the pollinators (i.e. differ in evenness). These points can be accounted for by using a standardized metric derived from the Kullback Leibler distance $\left(d_{\mathrm{i}}{ }^{\prime}\right)$, which was recently proposed as a met ric for specialization in quantitative plant pollinator networks (Blüthgen, Menzel \& Blüthgen 2006).

The importance of pollinator specialization for the degree of invasion may also depend on other reproductive character istics of plant species and might be confounded with them. Self compatible species, which do not exclusively rely on pollinators, and long flowering species, which have more time to wait for suitable pollinators, should be more likely to establish and spread after introduction to other parts of the world (Baker 1955). Indeed, several recent studies showed that self compatibility or autofertility (Rambuda \& Johnson 2004; van Kleunen \& Johnson 2007; van Kleunen et al. 2008; Hao et al. 2011; Pyšek et al. 2011; Knapp \& Kühn 2012) and long flowering duration (Cadotte \& Lovett Doust 2001; Lake \& Leishman 2004; Lloret et al. 2005) are fre quently related to the degree of invasion of alien plants. Fur thermore, length of flowering duration and the use of different pollination vectors were shown to act in concert to affect invasion success of introduced plant species in Germany (Knapp \& Kühn 2012). Therefore, we expect that the degree of invasion may be most restricted by pollinator specialization for self incompatible species and for short flowering species.

We assessed indices of specialization towards pollinator species and families for 118 European grassland species based on plant pollinator interaction data from 119 grassland sites in Germany. For these species, we also compiled data on their self compatibility and flowering duration and on their degrees of invasion (proportion of occupied regions) in seven large non Eurasian countries where they have established. We used these data to answer the following specific questions: (i) Does the degree of invasion in non native regions depend on specialization towards pollinators in the native range, self compatibility and flowering duration? (ii) Does the relationship between the degree of invasion and pollinator specialization depend on self compatibility and flowering duration?

\section{Materials and methods}

\section{DATA ON SPECIALIZATION TOWARDS POLLINATORS}

We collected data on plant pollinator interactions in the 'Biodiversity Exploratories', consisting of three major research areas (so called Exploratories) located in northern (Schorfheide Chorin), central (Hai nich Dun) and southern (Schwabische Alb) Germany (www.biodiver sity exploratories.de; Fischer et al. 2010). These regions cover study areas of different topographic and climatic characteristics (e.g. alti tude, precipitation) and a large proportion of the variation in grassland use in Central Europe (Fischer et al. 2010). In each of the Explorato ries, which cover areas of $7001300 \mathrm{~km}^{2}$, there are 50 experimental grassland plots of $50 \times 50 \mathrm{~m}$ selected by Fischer et al. (2010). From May to August 2008 (i.e. during peak flowering), we conducted 162 surveys in 119 of these 150 experimental grassland plots (Hainich Dun: 51, Schwabische Alb: 63, Schorfheide Chorin: 48). We could not sample 31 of the 150 plots because there were no flowering plants at the time of visit, mainly due to grazing or mowing. Most plots 
were sampled on a single day each, but some were sampled repeat edly to cover seasonal variation due to higher plant species diversity.

We observed plant pollinator interactions within $3 \mathrm{~m}$ wide stripes along the edges of the grassland plots, totalling $200 \mathrm{~m}$ in length. Each survey covered $6 \mathrm{~h}$ (three times $2 \mathrm{~h}$ ) of sampling between 8 a.m. and 6 p.m. depending on weather conditions, resulting in a total observa tion time of $972 \mathrm{~h}$ for all plots. One 'flowering unit' was defined as a unit of one (e.g. Ranunculaceae) or more flowers (e.g. Asteraceae) demanding an insect to fly in order to reach the next unit (Dicks, Corbet \& Pywell 2002). We recorded all flower visitors that touched the reproductive parts of a flowering unit and thus are likely to be pollinators and the plant species on which they were observed. Although performance of pollinators (sensu Ne'eman et al. 2010) differs between species and individuals of a species, visitation rate is regarded as a useful predictor of pollination (Vázquez, Morris \& Jordano 2005). For insect species that could not be determined in the field, specimens were collected to identify them in the laboratory. Thysanoptera (thrips) and Nitidulidae (sap beetles) were excluded from analysis as they are easily overlooked due to their small size, and thus may create a bias for some plants if collected erratically. The complete data set consisted of a total of 24665 interactions among 159 plant species, representing 23 plant families, and 764 pollinator species, representing 78 pollinator families.

Since the number of pollinator species increases with the number of observations of a plant, and to allow different quantitative weights for pollinators according to their contribution to plant visitation, we employed an information theoretical specialization metric $d_{\mathrm{i}}$ ' derived from the Kullback Leibler distance (Bluthgen 2010) to determine spe cialization towards pollinators. The metric $d_{i}^{\prime}$ ranges from 0 to 1 , with high values indicating specialization. Due to a null model based correction, this index has the advantage of being unaffected by varia tion in sampling effort or total interaction frequency and thus the incompleteness of sampled plant pollinator interactions (Bluthgen et al. 2007; Bluthgen 2010). Note that $d_{\mathrm{i}}$ ' also depends on the exclu siveness of the interactions (i.e. the degree to which a plant species is served by pollinators that do not serve other plant species; more details about the theory and calculation of the $d_{\mathrm{i}}$ ' metric are provided in Appendix S1 in Supporting Information). The $d_{\mathrm{i}}{ }^{\prime}$ metric was calcu lated for each plant species per site and sampling date and then aver aged per species to account for spatial and temporal variation. We distinguished $d_{\text {spec }}^{\prime}$ for plant pollinator interactions that are resolved on the pollinator species level from $d_{\text {fam }}^{\prime}$, for which pollinators and their interaction frequencies were pooled at the family level prior to analysis. Calculations of $d_{\mathrm{i}}$ ' were made with the function $d f u n$ in the package 'bipartite' (Dormann, Gruber \& Frund 2008; Dormann et al.
2009; see Bluthgen et al. 2007) of the free statistical software R (ver sion 2.10.0; R Development Core Team 2009).

\section{DATA ON DISTRIBUTION OF PLANT SPECIES IN NON NATIVE PARTS OF THE WORLD AND ON SELF COMPATIBILITY AND FLOWERING DURATION}

For the 159 European species, we obtained data on their distribution in 7 large non native countries on 4 non Eurasian continents from freely accessible online data bases and literature. We used the USDA Plants Data base (http://plants.usda.gov/, accessed 17 March 2010) for the USA and Canada, Australia's Virtual Herbarium (http://avh.ala.org.au/ accessed 16 February 2010) for Australia, the New Zealand Landcare Research data base (http://nzflora.landcareresearch.co.nz/, accessed 16 March 2010) for New Zealand, the Plants of Southern Africa Online Checklist (http://posa.sanbi.org/searchspp.php, accessed 22 April 2010) for South Africa and a study by Fuentes et al. (2010) for Chile and Argentina. For each plant species, we counted the number of regions (i.e. provinces, states, territories or districts) per country in which the species occurs, and calculated the proportion of occupied regions per non native country (i.e. regional abundance) as a measure of the degree of invasion. Although the proportion of occupied regions is a crude measure, higher resolution data (e.g. subregional or proportion of occupied habitats) are not available. The use of propor tion of occupied regions as a measure of degree of invasion is regarded ecologically consistent with the concept of invasiveness involving range expansion (sensu Richardson et al. 2000b; see Muth \& Pigliucci 2006; van Kleunen \& Johnson 2007). If a certain species did not occur in a country, we removed this species by country com bination from the data set, because absence of a species in a country might simply reflect that it has not been introduced and, thus, never had the opportunity to establish. Of the 159 plant species with polli nator specialization data, 133 have established in at least one of the 7 non native countries.

We extracted data on whether a plant species is potentially self compatible or not, and flowering duration (i.e. length of flowering duration in Germany in months, which ranged from 2 to 12 months; Table 1) from the BiolFlor data base (Klotz, Kuhn \& Durka 2002). For 120 of the 133 species that had established elsewhere, we had complete data for traits and degree of invasion (see Table S2). Two of these species are native to parts of Europe but are neophytes in Germany, and were excluded. The resulting data set included 118 plant species and 463 species by country combinations (Table 1). Flowering duration was slightly negatively correlated with $d_{\text {fam }}$ (Pear son's $r \quad-0.221, \quad n \quad 118, \quad P \quad 0.016), \quad$ but not with $d_{\text {spec }}^{\prime}$

Table 1. Numbers of self compatible (SC) and self incompatible (SI) plant species in our study and means and ranges of specialization indices as well as flowering durations per country. The numbers in parentheses behind the country names refer to the total number of regions per country

\begin{tabular}{|c|c|c|c|c|c|c|c|}
\hline \multirow[b]{2}{*}{ Country } & \multirow[b]{2}{*}{ Number of SC/SI species } & \multicolumn{2}{|l|}{$d_{\text {spec }}^{\prime}$} & \multicolumn{2}{|l|}{$d_{\text {fam }}^{\prime}$} & \multirow{2}{*}{$\begin{array}{l}\begin{array}{l}\text { Flowering } \\
\text { (months) }\end{array} \\
\text { Mean }\end{array}$} & duration \\
\hline & & Mean & Range & Mean & Range & & Range \\
\hline USA (51) & $70 / 32$ & 0.50 & 01 & 0.34 & $\begin{array}{ll}0 & 0.83\end{array}$ & 4.14 & 212 \\
\hline Canada (14) & $64 / 30$ & 0.50 & 01 & 0.33 & $\begin{array}{ll}0 & 0.83\end{array}$ & 4.16 & 212 \\
\hline Australia (8) & $48 / 30$ & 0.51 & 01 & 0.33 & $\begin{array}{ll}0 & 0.83\end{array}$ & 4.44 & 212 \\
\hline New Zealand (12) & $53 / 29$ & 0.49 & 01 & 0.32 & $\begin{array}{ll}0 & 0.83\end{array}$ & 4.41 & 212 \\
\hline Chile (52) & $23 / 13$ & 0.47 & 01 & 0.29 & $\begin{array}{ll}0 & 0.83\end{array}$ & 5.08 & 212 \\
\hline Argentina (24) & $23 / 11$ & 0.48 & 01 & 0.29 & $\begin{array}{ll}0 & 0.83\end{array}$ & 5.12 & 212 \\
\hline South Africa (9) & $23 / 14$ & 0.52 & 01 & 0.31 & $\begin{array}{ll}0 & 0.75\end{array}$ & 5.00 & 212 \\
\hline
\end{tabular}


$\left(\begin{array}{ll}r & -0.103, n \\ 118, P & 0.268\end{array}\right)$. This indicates that there was no strong multicollinearity between explanatory variables.

\section{STATISTICAL ANALYSIS}

To test how the degree of invasion (i.e. proportion of occupied regions per non native country) relates to the specialization indices (i.e. $d_{\text {spec }}^{\prime}$ and $d_{\text {fam }}^{\prime}$ ), self compatibility and flowering duration of our 118 study species, we applied linear mixed effects models using the 'nlme' package (Pinheiro et al. 2012) of the free statistical software R (version 2.10.0, R Development Core Team 2009). Because plant species might, as a consequence of a shared evolutionary history, not be independent data points (Felsenstein 1985), we incorporated phylo genetic information in the analyses. Therefore, we made a phyloge netic tree for our study species by pruning a recently published dated supertree for the European flora (Durka \& Michalski 2012; see Appendix S2, Fig. S2). We used a supertree approach instead of a supermatrix approach (e.g. Binda Emonds et al. 2003), because this allowed us to include all study species in the analyses. Because we had multiple observations for many of the species, we inserted short branched polytomies into the tree, resulting in a tree with 463 tips (see Appendix S2). The phylogenetic information of this tree was then included in the linear mixed effects models by specifying a phy logenetic correlation structure and applying a Grafen model of evolu tion (Grafen 1989). In other words, we used a regression that included expected variances of and covariances between species (and multiple observations per species) based on the phylogeny (Garland \& Ives 2000). We also tried models in which we used a Pagel model of evolution (Pagel 1999), but these models had higher AIC values, and were therefore not further considered. We included 'country' as a random factor to account for variation in proportion of occupied regions among countries, and each of the specialization indices, self compatibility, flowering duration and the interactions of the latter two with the specialization indices as fixed terms.

We tested whether each of the fixed terms had significant effects on the proportion of occupied regions of the species using likelihood ratio tests. Each of the two way interactions was tested by comparing the complete model with the model from which the two way interac tion of interest had been removed. Each of the main effects was tested by comparing a model without interactions (i.e. with main effects only) with the model from which the main effect of interest had been removed. For these model comparisons, we used maximum likelihood (ML) estimation. However, for the estimates of the effects in the complete model, we used restricted maximum likelihood (REML) estimation, because this method gives less biased estimates than ML (Zuur et al. 2009). To test whether variation among coun tries was significant, we checked whether the confidence intervals of the random factor 'country' were bounded away from zero (Pinheiro $\&$ Bates 2000). Prior to analysis, we logit transformed the proportion of occupied regions per non native country to meet model assump tions (Warton \& Hui 2011) and scaled all numerical explanatory vari ables to a mean of zero and a standard deviation of one to reduce possible collinearity among them and to facilitate comparisons between estimates (Schielzeth 2010).

\section{Results}

The specialization indices $d_{\text {spec }}^{\prime}$ and $d_{\text {fam }}^{\prime}$ were significantly correlated with each other (Pearson's $r \quad 0.648, n$ 118, $P<0.001$; Fig. S2). The model including $d_{\text {spec }}^{\prime}$ had a slightly lower AIC value than the one including $d_{\text {fam }}^{\prime}$ (Table 2),
Table 2. Results of the statistical analyses of the relationship between degree of invasion [measured as logit (proportion of occupied regions per non native country)], plant specialization indices ( $d_{\text {spec }}$ and $d^{\prime}$ fam $)$, self compatibility and flowering duration of 118 European grassland plant species introduced elsewhere. Shown are likelihood ratios $\left(\mathrm{X}^{2}\right.$; all with 1 d.f.) and their $P$ values for fixed terms, based on removal of the terms from the model, and the variance and its $95 \%$ confidence intervals for the random term. Significant effects $(P<0.05)$ are in boldface. The table also includes the AIC values and the estimates of Grafen's $\rho$ for the complete models based on restricted maximum likelihood (REML) estimation

\begin{tabular}{|c|c|c|c|c|}
\hline & \multicolumn{2}{|l|}{$d_{\text {spec }}^{\prime}$} & \multicolumn{2}{|l|}{$d_{\mathrm{fam}}^{\prime}$} \\
\hline & $X^{2}$ & $P$ & $\mathrm{X}^{2}$ & $P$ \\
\hline \multicolumn{5}{|l|}{ Fixed terms } \\
\hline Specialization index & 3.77 & 0.052 & 1.50 & 0.222 \\
\hline Self-compatibility & 1.17 & 0.279 & 0.87 & 0.351 \\
\hline Flowering duration & 26.08 & $<0.001$ & 24.08 & $<0.001$ \\
\hline $\begin{array}{l}\text { Specialization index } \times \\
\text { Self-compatibility }\end{array}$ & 3.07 & 0.080 & 1.50 & 0.220 \\
\hline $\begin{array}{l}\text { Specialization index } \times \\
\text { Flowering duration }\end{array}$ & 0.56 & 0.457 & 2.606 & 0.106 \\
\hline \multicolumn{5}{|l|}{ Random term } \\
\hline Country & $\begin{array}{l}0.868 \\
(0.477 \quad 1.578)\end{array}$ & & $\begin{array}{l}0.876 \\
(0.475 \quad 1.616)\end{array}$ & \\
\hline AIC & 1740.688 & & 1742.995 & \\
\hline Grafen's $\rho$ & 0.204 & & 0.198 & \\
\hline
\end{tabular}

indicating that the model with $d_{\text {spec }}^{\prime}$ best explained the varia tion in the degree of invasion.

In both models, the degree of invasion was significantly positively affected by flowering duration (Table 2 and Fig. 1). The means $( \pm \mathrm{SE})$ of the proportion of occupied regions for the 20 species with the shortest and the ones with the longest flowering durations were $0.308( \pm 0.041)$ and 0.561 ( \pm 0.047$)$, respectively. The main effects of self compatibility and specialization indices were not significant (Table 2). However, in the model including $d_{\text {spec }}^{\prime}$, there was a margin ally significant positive effect of the specialization index on degree of invasion ( $P$ 0.052, Table 2 and Fig. 1). This effect was not apparent though when we did not correct for phylogenetic non independence of the species, as the means ( \pm SE) of the proportion of occupied regions for the 20 spe cies with the lowest and the ones with the highest $d_{\text {spec }}^{\prime}$ were $0.348( \pm 0.035)$ and $0.340( \pm 0.053)$, respectively. In the model, which included phylogenetic information, this effect of $d_{\text {spec }}^{\prime}$ was mainly caused by the self compatible species, as indicated by the marginally significant interaction between

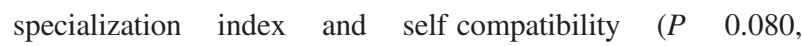
Table 2 and Fig. 1).

\section{Discussion}

Our study showed that out of the three reproductive character istics included in our study, flowering duration was most strongly related to the degree of invasion of European plant species in non native regions. The main effects of self compatibility and specialization towards pollinators in the 
Fig. 1. Fitted relationships of degree of inva sion, measured as logit (proportion of occu pied regions), with flowering duration and Kullback Leibler distance derived indices of specialization towards (a) pollinator species $\left(d_{\text {spec }}^{\prime}\right)$ and (b) pollinator families $\left(d^{\prime}{ }_{\text {fam }}\right)$ for self compatible (grey) and self incompatible (white) species. Significances are given in Table 2, and estimates and standard errors of the model terms are given in Table S3.
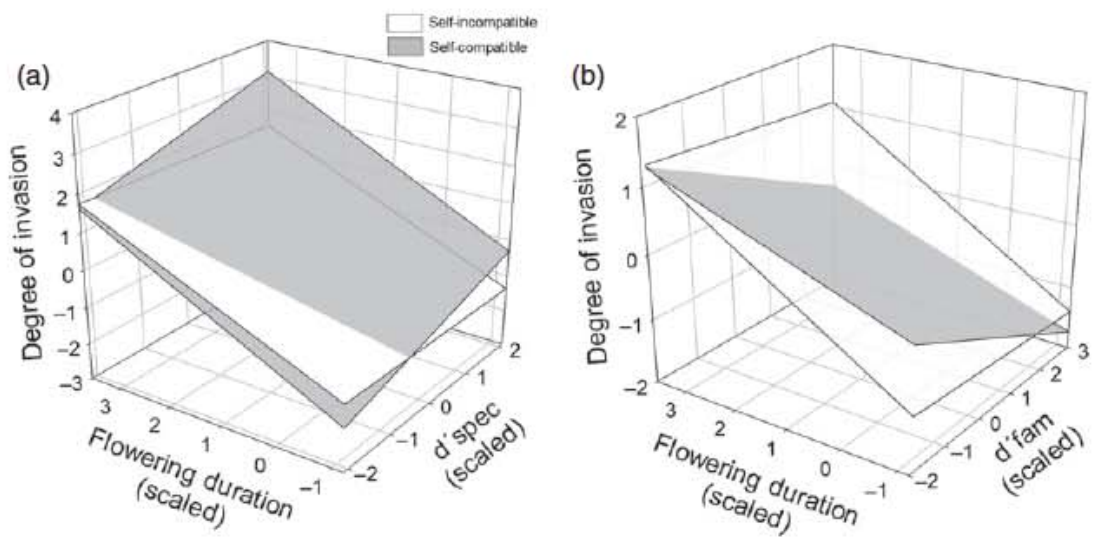

native range were not significant. However, there was a trend that, among self compatible plant species, the ones that were more strongly specialized towards pollinator species had a higher degree of invasion. This suggests that the effects of pollinator specialization on the degree of invasion may depend on the mating system.

\section{EFFECTS OF POLLINATOR SPECIALIZATION ON THE DEGREE OF INVASION}

A recent study, using a data base of associations between invertebrates and plants in north western Europe, showed that the spread of alien plant species in the Czech Republic is positively correlated with the number of pollinators that are known to visit these species (Pyšek et al. 2011). This could indicate that, among the alien plant species, pollinator generalists have become more widespread. However, in con trast to our study, Pyšek et al. (2011) used counts of polli nator species and functional groups from the non native range, and they could not correct for observation frequency. Consequently, it is likely, as suggested by Pyšek et al. (2011) themselves, that the positive association between dis tribution and pollinator diversity in the non native range reflects that widespread alien plant species had a higher chance to accumulate pollinator species. Our approach of determining pollinator specialization in the native range, while accounting for observation frequency, and relating it to degree of invasion in non native ranges, is a straightfor ward test of the potential role of pollinator specialization for invasiveness.

The effect of specialization towards pollinators was not sig nificant, and there was even a trend that more strongly spe cialized species had a higher instead of a lower degree of invasion in non native regions. This indicates that pollinator specialization may not be a huge barrier to becoming inva sive, and is in line with some recent case studies showing that apparently specialized plant species can become invasive (Rodger, van Kleunen \& Johnson 2010; Ollerton et al. 2012). The next step for arriving at a better mechanistic understand ing of the role of pollinator generalization in invasiveness would be to test whether pollinator generalization as measured in the native range is positively associated with pol linator generalization in the non native range.
We found that for self compatible species, there was a slight positive effect of pollinator specialization on the degree of invasion, whereas for self incompatible species there was no apparent effect of pollinator specialization. Although this interaction between self compatibility and pollinator special ization was not statistically significant $\left(\begin{array}{ll}P & 0.080\end{array}\right)$, this result was opposite to our expectation that pollinator specialization should have a negative effect on degree of invasion of self incompatible species, which are fully reliant on pollinators. The absence of a negative relationship between pollinator spe cialization and degree of invasion in our study may be spe cific for plant species that are native to Europe. Most of the major functional groups of pollinators (e.g. bees, flies, butter flies) in Europe also occur in other continents and may thus be likely to visit the European plants in other continents. However, for plant species native to continents with relatively unique groups of functional pollinators (e.g. hummingbirds, bats), a negative relationship between pollinator specialization in the native range and degree of invasion elsewhere might be more likely. A potential reason for the slight positive effect of pollinator specialization on the degree of invasion of self compatible species could be that self compatible species with few pollinators in the native range may have a higher capacity for autonomous self fertilization and therefore have a higher degree of invasion. However, because we do not have quantitative data on the capacity for autonomous self fertiliza tion of our study species, we could not test this.

\section{EFFECTS OF SELF COMPATIBILITY ON THE DEGREE OF INVASION}

A number of recent studies found evidence that self compati bility and autonomous seed production contribute to the establishment and spread of alien species (Rambuda \& John son 2004; van Kleunen \& Johnson 2007; van Kleunen et al. 2008; Hao al. 2011; Pyšek et al. 2011; but see Sutherland 2004; Burns et al. 2011 for exceptions). In our study, there was no significant effect of self compatibility on the degree of invasion. However, for species with high $d_{\text {spec }}^{\prime}$ values, the self compatible ones tended to have a higher degree of inva sion than the self incompatible ones (Fig. 1a). The opposite trend was apparent for species with more generalized pollina tion systems. Most probably, this contrast reflects that species 
with specialized pollination systems are less likely to attract pollinators in the non native range and thus rely more on sel fing as a means of reproductive assurance.

\section{EFFECTS OF FLOWERING DURATION ON THE DEGREE OF INVASION}

Flowering phenology is a fundamental factor in shaping plant pollinator interactions as plants can use only those poll inators whose activity periods overlap with the flowering peri ods (Parker 1997). Having a long flowering period increases the likelihood that at least some flowers on a plant will be visited and successfully pollinated. It has frequently been found that long flowering periods are positively correlated with invasiveness in the non native range of alien species (Lloret et al. 2005; Küster et al. 2008). Although flowering durations may change after introduction particularly after introduction into areas with a climate different from that in the native range our results show that flowering duration as assessed in the native range is also related to the degree of invasion elsewhere. Because species with long flowering durations are more attractive as ornamental plants, the associ ation between invasiveness and flowering duration could also, at least partly, reflect an introduction bias (see Chrobock et al. 2011). However, because most of our study species have neither showy flowers nor showy foliage, it is unlikely that many of them were introduced elsewhere for ornamental purposes. Therefore, we conclude that it is very likely that a long flowering duration increases invasiveness because it increases the chance of reproduction.

\section{COMPARISON OF THE SPECIALIZATION INDICES}

A plant species that can be pollinated by a wide range of functionally different pollinators from different families should be more likely to find a suitable pollinator than one that relies on a single functional group of pollinators. There fore, we expected that a specialization index based on number of pollinator families would be sufficient to characterize polli nator specialization of introduced plant species. However, this was not supported by our results, as the AIC value of the model with $d_{\text {fam }}^{\prime}$ was slightly higher indicating a lower fit than that of the model with $d_{\text {spec }}^{\prime}$. This suggests that it is not sufficient to determine pollinators only at the family level if one wants to quantify pollinator specialization. Recent studies have shown that the degree of pollinator specialization is related to floral morphology (e.g. Stang, Klinkhamer \& van der Meijden 2006), which suggests that measurements of flo ral morphology might be an alternative, less labour intensive way to infer pollinator specialization. Future studies should therefore test explicitly how floral morphology is related to the degree of invasiveness of plant species.

\section{Conclusions}

Because of their direct link to demographic processes, repro ductive characteristics are frequently considered to be key traits for invasiveness (Richardson et al. 2000b). Conse quently, reproductive traits are among the species character istics used to assess the risk that alien species might become invasive (Pheloung, Williams \& Halloy 1999), and these traits are also considered in the development of strategies to manage species that have already become invasive (Viegi 2001). However, the empirical basis for this has been miss ing as only few studies have explicitly tested the importance of reproductive characteristics for invasiveness. Here, we showed that long flowering duration is related to the degree of invasion in other parts of the world and that there was tentative evidence suggesting that pollinator generalization in the native range may interact with self compatibility in determining invasiveness. Based on our findings and the ones of others (e.g. Cadotte \& Lovett Doust 2001; van Kle unen et al. 2008; Pyšek et al. 2011), we suggest that these traits indeed need to be considered in risk assessment and management strategies of introduced entomophilous plant species.

\section{Acknowledgements}

For the identification of insects, we thank W. Adaschkiewitz, R. Heiß, G. Merkel-Wallner, B. Merz, V. Michelsen, S. Prescher, H.-G. Rudzinski, A. Stark, K. Szpila, M. Tospann, M. von Tschirnhaus, H.-P. Tschorsnig (Diptera); D. Doczkal (Apidae, Syrphidae); M. Fellendorf, M. Hermann, V. Mauss, H. Schwenninger (Apidae); K. Horstmann, S. Klopfstein (Ichneumonidae), L. Hubweber, P. Sprick (Coleoptera); M. Krauss, B. Wende (Symphyta); A. Melber (Heteroptera); R. Schultz (Formicidae); and M. Wölfling (Lepidoptera). We thank the managers of the three exploratories, S. Renner, S. Gockel, A. Hemp and M. Gorke and S. Pfeiffer for their work in maintaining the plot and project infrastructure and E. K. V. Kalko, E. Linsenmair, D. Hessenmöller, J. Nieschulze, D. Prati, I. Schöning, F. Buscot, E.-D. Schulze and W. W. Weisser for their role in setting up the Biodiversity Exploratories project. W. Dawson and R. P. Rohr provided statistical advice. This study was financed by the Swiss National Science Foundation (SNF), grant no. 31003A-117722, by the DFG Priority Program 1374 'Infrastructure-Biodiversity-Exploratories' (LI150/20-1, FI1246/6-1,9-1), by the DFG project KL $1866 / 3-1$ and by the EU in the FP7 collaborative project 'STEP Status and Trends of European Pollinators'. Field work permits were given by the responsible German state environmental offices of Baden-Württemberg, Brandenburg and Thuringia (according to state environmental laws, e.g. $\$ 72$ BbgNatSchG).

\section{References}

Baker, H.G. (1955) Self-compatibility and establishment after "long-distance" dispersal. Evolution, 9, 347349.

Baker, H.G. (1974) The evolution of weeds. Annual Review of Ecology and Systematics, 5, 124

Binda-Emonds, O.R.P., Jones, K.E., Price, S.A., Grenyer, R., Cardillo, M., Habib, M., Purvis, A. \& Gittleman, J.L. (2003) Supertrees are a necessary not-so-evil: a comment on Gatesy et al.. Systematic Biology, 52, 724729.

Blackburn, T.M., Pysek, P., Bacher, S., Carlton, J.T., Duncan, R.P., Jarosik, V., Wilson, J.R.U. \& Richardson, D.M. (2011) A proposed unified framework for biological invasions. Trends in Ecology and Evolution, 26, 333 339.

Blüthgen, N. (2010) Why network analysis is often disconnected from community ecology: a critique and an ecologist's guide. Basic and Applied Ecology, 11, 185195.

Blüthgen, N., Menzel, F. \& Blüthgen, N. (2006) Measuring specialization in species interaction networks. BMC Ecology, 6, 9.

Blüthgen, N., Menzel, F., Hovestadt, T., Fiala, B. \& Blüthgen, N. (2007) Specialization, constraints, and conflicting interests in mutualistic networks. Current Biology, 17, 341346.

Burns, J.H., Ashman, T.-L., Steets, J.A., Harmon-Threatt, A. \& Knight, T.A. (2011) A phylogenetically controlled analysis of the roles of reproductive traits in plant invasions. Oecologia, 166, 10091017. 
Cadotte, M.W. \& Lovett-Doust, J. (2001) Ecological and taxonomic differences between native and introduced plants of southwestern Ontario. Ecoscience, $\mathbf{8}$, 388395 .

Chrobock, T., Kempel, A., Fischer, M. \& van Kleunen, M. (2011) Introduction bias: cultivated alien plant species germinate faster and more abundantly than native species in Switzerland. Basic and Applied Ecology, 12, 244250.

Dicks, L.V., Corbet, S.A. \& Pywell, R.F. (2002) Compartmentalization in plant-insect flower visitor webs. Journal of Animal Ecology, 71, 3243.

Dormann, C.F., Gruber, B. \& Fründ, J. (2008) Introducing the bipartite package: analysing ecological networks. $R$ News, $\mathbf{8} / \mathbf{2}, 811$.

Dormann, C.F., Fründ, J., Blüthgen, N. \& Gruber, B. (2009) Indices, graphs and null models: analyzing bipartite ecological networks. Open Ecology Journal, 2, 724 .

Durka, W. \& Michalski, S.G. (2012) DaPhnE a dated phylogeny of a large European flora for phylogenetically informed ecological analyses. Ecology, 93, 22972297.

Felsenstein, J. (1985) Phylogenies and the comparative method. American Naturalist, 125, 115

Fenster, C.B., Armbruster, W.S., Wilson, P., Dudash, M.R. \& Thomson, J.D. (2004) Pollination syndromes and floral specialization. Annual Review of Ecology, Evolution and Systematics, 35, 375403.

Fischer, M., Bossdorf, O., Gockel, S., Hänsel, F., Hemp, A., Hessenmöller, D. et al. (2010) Implementing large-scale and long-term functional biodiversity research: the biodiversity exploratories. Basic and Applied Ecology, 11, 473 485

Fontaine, C., Thébault, E. \& Dajoz, I. (2009) Are insect pollinators more generalist than insect herbivores? Proceedings of the Royal Society B Biological Sciences, 276, 30273033.

Fuentes, N., Ugarte, E., Kühn, I. \& Klotz, S. (2010) Alien plants in southern South America. A framework for evaluation and management of mutual risk of invasion between Chile and Argentina. Biological Invasions, 12, 3227 3236.

Garland, T. Jr \& Ives, A.R. (2000) Using the past to predict the present: confidence intervals for regression equations in phylogenetic comparative methods. American Naturalist, 155, 346364.

Grafen, A. (1989) The phylogenetic regression. Philosophical Transactions of the Royal Society B, 326, 119157.

Gross, C.L., Gorrell, L., MacDonald, M.J. \& Fatemi, M. (2010) Honeybees facilitate the invasion of Phyla canescens (Verbenaceae) in Australia no bees, no seed!. Weed Research, 50, 364372.

Hao, J.H., Qiang, S., Chrobock, T., van Kleunen, M. \& Liu, Q.Q. (2011) A test of Baker's Law: breeding systems of invasive species of Asteraceae in China. Biological Invasions, 13, 571580.

van Kleunen, M. \& Johnson, S.D. (2007) Effects of self-compatibility on the distribution range of invasive European plants in North America. Conservation Biology, 21, 15371544.

van Kleunen, M., Manning, J.C., Pasqualetto, V. \& Johnson, S.D. (2008) Phylogenetically independent associations between autonomous self-fertilization and plant invasiveness. The American Naturalist, 171, 195201.

van Kleunen, M., Dawson, W., Schlaepfer, D., Jeschke, J.M. \& Fischer, M. (2010) Are invaders different? A conceptual framework of comparative approaches for assessing determinants of invasiveness. Ecology Letters, 13, 947958

Klotz, S., Kühn, I. \& Durka, W. (2002) BiolFlor eine Datenbank zu biologisch-ökologischen Merkmalen der Gefässpflanzen in Deutschland. Schriftenreihe für Vegetationskunde, 38. Bundesamt für Naturschutz, Bonn, Germany.

Knapp, S. \& Kühn, I. (2012) Origin matters: widely distributed native and nonnative species benefit from different functional traits. Ecology Letters, 15 696 703, doi:10.1111/j.1461-0248.2012.01787.x.

Küster, E.C., Kühn, I., Bruelheide, H. \& Klotz, S. (2008) Trait interactions help to explain plant invasion success in the German flora. Journal of Ecology, 96, 860868 .

Lake, J.C. \& Leishman, M.R. (2004) Invasion success of exotic plants in natural ecosystems: the role of disturbance, plant attributes and freedom from herbivores. Biological Conservation, 117, 215226.

Lloret, F., Médail, F., Brundu, G., Camarda, I., Moragues, E., Rita, J., Lambdon, P. \& Hulme, P.E. (2005) Species attributes and invasion success by alien plants on Mediterranean islands. Journal of Ecology, 93, 512520.

Memmott, J. \& Waser, N.M. (2002) Integration of alien plants into a native flower-pollinator visitation web. Proceedings of the Royal Society B Biological Sciences, 269, 23952399.

Muñoz, A.A. \& Cavieres, L.A. (2008) The presence of a showy invasive plant disrupts pollinator service and reproductive output in native alpine species only at high densities. Journal of Ecology, 96, 459467.
Muth, N.Z. \& Pigliucci, M. (2006) Traits of invasives reconsidered: phenotypic comparisons of introduced invasive and introduced noninvasive plant species within two closely related clades. American Journal of Botany, 93, 188196.

Ne'eman, G., Jürgens, A., Newstrom-Lloyd, L., Potts, S.G. \& Dafni, A. (2010) A framework for comparing pollinator performance: effectiveness and efficiency. Biological Reviews, 85, 435541.

Ollerton, J., Winfree, R. \& Tarrant, S. (2011) How many flowering plants are pollinated by animals? Oikos, 120, 321326.

Ollerton, J., Killick, A., Lamborn, E., Watts, S. \& Whiston, M. (2007) Multiple meanings and modes: on the many ways to be a generalist flower. Taxon, 56, 717728

Ollerton, J., Watts, S., Connerty, S., Lock, J., Parker, L., Wilson, I. et al. (2012) Pollination ecology of the invasive tree tobacco Nicotiana glauca: comparisons across native and non-native ranges. Journal of Pollination Ecology, 9, 8595.

Pagel, M. (1999) Inferring the historical patterns of biological evolution. Nature, 401, 877884

Parker, I.M. (1997) Pollinator limitation of Cytisus scoparius (Scotch broom), an invasive exotic shrub. Ecology, 78, 14571470.

Parker, I.M. \& Haubensak, K.A. (2002) Comparative pollinator limitation of two non-native shrubs: do mutualisms influence invasions? Oecologia, 130, 250258.

Pattemore, D.E. \& Wilcove, D.S. (2012) Invasive rats and recent colonist birds partially compensate for the loss of endemic New Zealand pollinators. Proceedings of the Royal Society B Biological Sciences, 279, 15971605.

Pheloung, P.C., Williams, P.A. \& Halloy, S.R. (1999) A weed risk assessment model for use as a biosecurity tool evaluating introductions. Journal of Environmental Management, 57, 239251.

Pinheiro, J.C. \& Bates, D.M. (2000) Mixed-Effects Models in S and S-PLUS. Springer Verlag New York, USA.

Pinheiro, J., Bates, D., DebRoy, S. \& Sarkar, D. \& the R Development Core Team (2012) nlme: linear and non-linear mixed effects models. R package version 3.1-103.

Pysek, P., Jarosik, V., Chytry, M., Danihelka, J., Kühn, I., Pergl, J., Tichý, L., Biesmeijer, J.C., Ellis, W.E., Kunin, W.E. \& Stettele, J. (2011) Successful invaders co-opt pollinators of native flora and accumulate insect pollinators with increasing residence time. Ecological Monographs, 81, 277293.

R Development Core Team (2009) R: A Language and Environment for Statistical Computing. R Foundation for Statistical Computing, Vienna, Austria

Rambuda, T.D. \& Johnson, S.D. (2004) Breeding systems of invasive alien plants in South Africa: does Baker's rule apply? Diversity and Distributions, 10, 409416

Richardson, D.M., Pysek, P., Rejmánek, M., Barbour, M.G., Panetta, D. \& West, C.J. (2000a) Naturalization and invasion of alien plants: concepts and definitions. Diversity and Distributions, 6, 93107.

Richardson, D.M., Allsopp, N., D'Antonio, C.M., Milton, S.J. \& Rejmánek, M. (2000b) Plant invasions the role of mutualisms. Biological Reviews, 75 , 6593.

Rodger, J.G., van Kleunen, M. \& Johnson, S.D. (2010) Does specialized pollination impede plant invasions? International Journal of Plant Sciences, 171, 382391.

Schielzeth, H. (2010) Simple means to improve the interpretability of regression coefficients. Methods in Ecology and Evolution, 1, 103113.

Stang, M., Klinkhamer, P.G.L. \& van der Meijden, E. (2006) Size constraints and flower abundance determine the number of interactions in a plant-flower visitor web. Oikos, 112, 111121

Stout, J.C., Kells, A.R. \& Goulson, D. (2002) Pollination of the invasive exotic shrub Lupinus arboreus (Fabaceae) by introduced bees in Tasmania. Biological Conservation, 106, 425434

Sutherland, S. (2004) What makes a weed a weed: life history traits of native and exotic plants in the USA. Oecologia, 141, 2439

Vázquez, D.P., Morris, W.F. \& Jordano, P. (2005) Interaction frequency as a surrogate for the total effect of animal mutualists on plants. Ecology Letters, 8, 10881094 .

Viegi, L. (2001) Investigations on some reproductive features of invasive alien plants in Italy. Plant Invasions: Species Ecology and Management (eds. G. Brundu, J. Brock, I. Camarda, L. Child \& M. Wade), pp. 255 262. Back huys Publishers, Leiden, The Netherlands.

Vilà, M., Bartomeus, I., Dietzsch, A.C., Petanidou, T., Steffan-Dewenter, I., Stout, J.C. \& Tscheulin, T. (2009) Invasive plant integration into native plant-pollinator networks across Europe. Proceedings of the Royal Society B Biological Sciences, 276, 38873893. 
Warton, D.I. \& Hui, F.K.C. (2011) The arcsine is asinine: the analysis of proportions in ecology. Ecology, 92, 310.

Waser, N.M., Chittka, L., Price, M.V., Williams, N.M. \& Ollerton, J. (1996) Generalization in pollination systems, and why it matters. Ecology, 77, 10431060.

Zuur, A.F., Ieno, E.N., Walker, N.J., Savaliev, A.A. \& Smith, G.M. (2009) Mixed Effects Models and Extensions in Ecology with R. Springer Science + Business Media, New York, USA.
Table S1. Examples for calculating $d_{\mathrm{i}}^{\prime}$.

Figure S1. Correlation between $d_{\text {fam }}^{\prime}$ and $d_{\text {spec }}^{\prime}$.

Table S2. List of the 118 study species with data on specialization towards pollinators.

Appendix S2. Construction of the phylogeny of the 118 European grassland species.

Figure S2. Phylogeny of the 118 European grassland species.

Appendix S3. Model estimates.

Table S3. Results of the statistical analyses.

Appendix S1. Properties of the specialization metric $d^{\prime}$. 